\title{
Environment-dependent heterosis in Drosophila melanogaster
}

\author{
A. DOMÍNGUEZ and J. ALBORNOZ \\ Departamento de Genética, Universidad de Oviedo, 33071 Oviedo, Spain
}

\begin{abstract}
Summary
Heterosis for viability, rate of development and fecundity were measured in optimal or stress environments (development at high larval density for preadult traits and both crowded development and low temperature for egg laying) using diallel crosses among 5 inbred lines of $D$. melanogaster from different geographic origins. Some cases of significant heterosis for viability and rate of development were found, but the results did not permit any general conclusion to be drawn about the effect of environment for these traits. Every pair of lines displayed heterosis for fecundity both under optimal and crowded development conditions, while only 2 pairs of lines showed significant heterosis for fecundity at low temperature. Contrary to what is usually found for most traits, heterosis for fecundity was greater in the optimal environment. Hybrids were more affected by environmental stress than their inbred parents, but the error variance within environment was lower for the hybrids. This suggests that the greater homeostasis of hybrids to minor changes in environinent can not be extended to major changes in the environment in which different sets of genes may be implicated.
\end{abstract}

Key words: Drosophila melanogaster, heterosis, genotype $\times$ environment interaction.

\section{Résumé}

\section{Hétérosis dépendante du milieu chez Drosophila melanogaster}

A partir d'un diallèle entre 5 lignées de $D$. melanogaster de différentes origines géographiques, on a mesuré l'hétérosis sur la viabilité, la vitesse de développement et la fécondité dans un milieu optimal ou de stress (haute densité larvaire pour la viabilité et la vitesse de développement et développement à haute densité larvaire et basse température pour la ponte d'œufs). On a trouvé quelques cas d'hétérosis sur la viabilité et la vitesse de développement, mais les résultats ne permettent pas de conclure sur une tendance générale de la variation de l'hétérosis en fonction du milieu pour ces caractères. Toutes les paires de lignées présentent une hétérosis sur la fécondité, à la fois en milieu optimal et en milieu à haute densité larvaire, alors que seules 2 paires de lignées présentent une hétérosis significative pour la fécondité à basse température. Contrairement à ce qu'on trouve habituellement pour la plupart des caractères, l'hétérosis sur la fécondité est plus importante dans le milieu le plus favorable. Les hybrides sont plus affectés par un stress environnemental que leurs parents consanguins, tandis que la variance d'erreur intra-environnement est plus faible chez les hybrides. Ce fait suggère que la plus grande homéostasie des hybrides face à des modifications mineures de milieu peut ne pas se maintenir lorsque se produisent des modifications majeures du milieu, dans lesquelles différents ensembles de gènes peuvent être impliqués.

Mots clés : Drosophila melanogaster, hétérosis, interaction génotype $\times$ milieu. 


\section{Introduction}

The magnitude of heterosis is conditioned very much by the environment (for a review see BARLow, 1981). For most traits, heterosis appears to be greater in suboptimal environments. This is in accordance with the hypothesis of LERNER (1970) that hybrids are likely to be more homeostatic than homozygotes in the presence of environmental variation. As a consequence of greater homeostasis, hybrid superiority would be more pronounced in suboptimal environments.

Drosophila hybrids were shown to display lesser variation than parental lines within a given environment for a variety of traits : survival, size and developmental time (Robertson \& REeve, 1952) ; fecundity (RoberTson \& REeve, 1955) ; wing and thorax length and percentage emergence (TANTAWY, 1957).

A number of studies in Drosophila have also shown greater heterosis under extreme environmental conditions than under optimal ones. Most of these studies dealt with viability (Dobzhansky et al., 1955 ; Dobzhansky \& Levene, 1955 ; Parsons, 1959 ; Fontdevila, 1970 ; Young, 1971 ; Tachida \& Mukai, 1985) and with longevity (Parsons, 1966 ; Clare \& Luckinbill, 1985). Nevertheless, Sang (1964) found clear differential effects of departures from optimal nutritional conditions on the performance (survival, weight and developmental rate) of various genotypes, and the crosses were not better "buffered" in this respect.

This paper reports a study of hybrid vigour in Drosophila melanogaster over some optimal and suboptimal environmental conditions. Three fitness traits, viability, developmental time and fecundity were measured in the same lines and hybrids. With this information it was possible to test the homeostasis of the hybrids for different traits within and across environments.

\section{Materials and methods}

Five inbred lines of D. melanogaster were used: Teverga-5 (Spain), Crkwenica (Czechoslovakia), Israel (Israel), Kreta-75 (Greece) and Hampton Hill (Great Britain). The last four lines came from the Umeå Drosophila Stock Center.

The culture medium used throughout the experiments was composed of $12 \mathrm{~g}$ of agar, $100 \mathrm{~g}$ of sugar, $100 \mathrm{~g}$ of baker's yeast and $5 \mathrm{ml}$ of propionic acid per litre of water. For oviposition scores, $4 \mathrm{~g} / \mathrm{l}$ of charcoal were added to the medium, and a spot of live yeast was put on the surface.

Attention was paid to 3 traits : viability, rate of development and fecundity under optimal and one or two suboptimal environmental conditions. Both viability and developmental time were scored under 2 environmental conditions : " optimum density $\left(30\right.$ eggs per vial, $\left.24^{\circ} \mathrm{C}\right)$ and « high density» $\left(300\right.$ eggs per vial, $\left.24^{\circ} \mathrm{C}\right)$. Fecundity was scored under 3 environmental conditions : "optimal conditions » (females developed under the defined optimal developmental conditions were allowed to oviposit at $24^{\circ} \mathrm{C}$ ), « crowded development » (females developed under the defined 
high density environment were allowed to oviposit at $24^{\circ} \mathrm{C}$ ) and " low temperature " (females from the optimum density conditions were allowed to oviposit at $17^{\circ} \mathrm{C}$ ).

Trait analysed

Viability

Rate of development
Diallel crosses

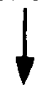

Eggs from each cross

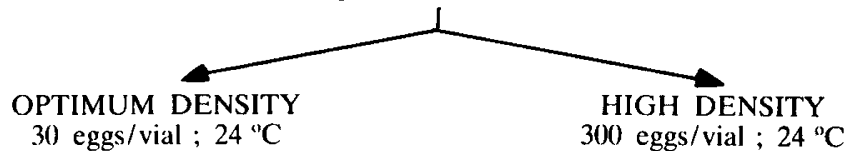

(5 replicates)

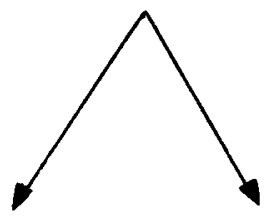

( 2 replicates)

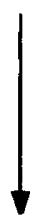

LOW TEMPERA

(5 replicates)

24 " $\mathrm{C}$

(5 replicates)

CROWDED DEVELOPMENT 24 " $\mathrm{C}$

(5 replicates)

FIG. 1

Diagrammatic representation of the experimental design. See text for more details.

Figure 1 shows a description of the experimental procedure. A $5 \times 5$ diallel cross, including reciprocals, was performed. Forty males and 40 females were mated to produce each of the 25 crosses. Then females were allowed to oviposit for 16 hours. Random samples of eggs were placed in glass vials $(25 \mathrm{~mm} \times 115 \mathrm{~mm})$ containing $4.5 \mathrm{ml}$ of culture medium, 30 (optimum density, 5 replicates) or 300 (high density, 2 replicates) per vial, and allowed to develop at $24 \pm 1^{\circ} \mathrm{C}$. The number of replicates was different for the 2 density treatments because the treatment itself implies more individuals to be measured under crowded development than under optimal conditions. The number of adults which emerged from these cultures was counted each day. Viability was then scored as the proportion of eggs that became imagos in each vial. Rate of development was scored as the reciprocal of the mean time of development in days in each vial.

Females emerging from optimum density and high density cultures in the 2 or 3 days of maximum emergence were selected for oviposition experiments. Two females were placed into each vial together with 2 young males. Females from optimum density were allowed to oviposit at $24 \pm 1{ }^{\circ} \mathrm{C}$ (optimal conditions) or at $17 \pm 1^{\circ} \mathrm{C}$ (low temperature). Females from high density cultures were placed at $24 \pm 1^{\circ} \mathrm{C}$ (crowded development). Five replicates were set up for each cross and environmental condition. Fecundity was scored as the average daily egg laying per female in the fourth and fifth days of age.

Rate of development was preferred to developmental time because it had more satisfactory statistical properties. Error variances of developmental time changed with 


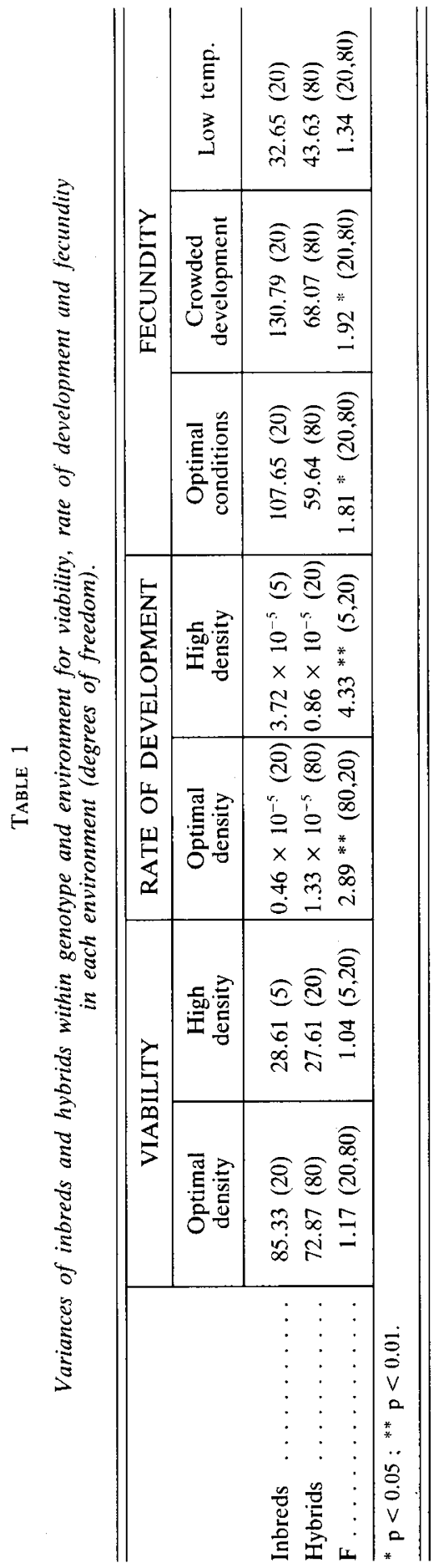


treatments $\left(\mathrm{F}_{(25.10(x))}=4.06 ; \mathrm{p}<0.001\right)$ while rate of development had homogeneous variances over treatments $\left(\mathrm{F}_{(25.100)}=1.24\right.$; non significant). Although variances for viability differed between treatments at the 1 p. 100 level $\left(F_{(100.25)}=2.78\right)$, analyses were conducted on untransformed percentages because arc sin $\sqrt{\mathrm{p}}$ transformation increased variance inequality $\left(\mathrm{F}_{(100,25)}=4.28 ; \mathrm{p}<0.001\right)$. Error variances for fecundity differed between treatments at the 1 p. 100 level $\left(\chi_{2 \text { d.f. }}^{2}\right.$ on Barttlet's test of homogeneity of variances $=11.30$ ), but there was no clear relationship between means and variances. The log. transformation increased the inequality of variances $\left(\chi_{2 \text { d.f. }}^{2}\right.$ on Bartlett's test of homogeneity of variances $=116.83$ ), so, the analyses of fecundity were made on untransformed data.

A two-way analysis of variance was conducted for each trait where the genotype and the environmental condition were considered fixed factors. The genotype and interaction effects were further divided into inbreds, hybrids, reciprocals and hybrids vs. inbreds components. Analyses of viability and rate of development were conducted following the computational formulas for different numbers of replicates among treatments from SNEdecor \& Cochran (1967). Finally, heterosis of each line pair and mean heterosis were estimated for each trait and environmental condition as $\vec{F}_{1}-\vec{P}$. Significance was tested by the t-test.

\section{Results}

Error variances (variances between replicates within genotype and treatment) of inbred lines and hybrids are compared in table 1. Error variances of inbred lines and hybrids for viability were not different. The error variance of inbred lines for rate of development under optimum density was less than that of hybrids due to the high error variance of the crosses between Hampton Hill and Crkwenica $\left(8.80 \times 10^{-5}\right.$ for $q q$ $\mathrm{HH} \times \mathrm{O}^{\prime \prime} \mathrm{O}^{7} \mathrm{Crk}$ and $6.27 \times 10^{-5}$ for the reciprocal). The inbred lines showed larger error variance for rate of development than the hybrids under high density. Inbreds were more variable than hybrids for fecundity in optimal and crowded development conditions, but not at low temperature.

Table 2 shows an analysis of genotype, environment and genotype $\times$ environment interaction effects on the 3 traits. From the analysis of viability (table $2 a$ ), significant effects of genotype and environment were shown, while their interaction was not significant. The main genotypic effects were all significant except the hybrids vs. inbreds component, which shows that there was not an overall significant heterosis for the trait. When dividing the interaction into its components it was found that the inbreds component was significant at the 5 p. 100 level.

The genotype, environment and interaction effects on the rate of development were significant (table 2b). All the main genetic components were significant. The significant variation between inbreds shows that there was additive variation for the trait. There were also reciprocal effects, and heterosis for the trait as shown by the hybrids vs. inbreds component. Interaction was due to the hybrids and reciprocals components. The hybrids vs. inbreds component of interaction was not significant, which shows that heterosis did not change between the 2 environmental conditions. 
TABLE 2

Analysis of genotype, environment and interaction effects on viability (a), rate of development (b) and fecundity (c).

a) Viability

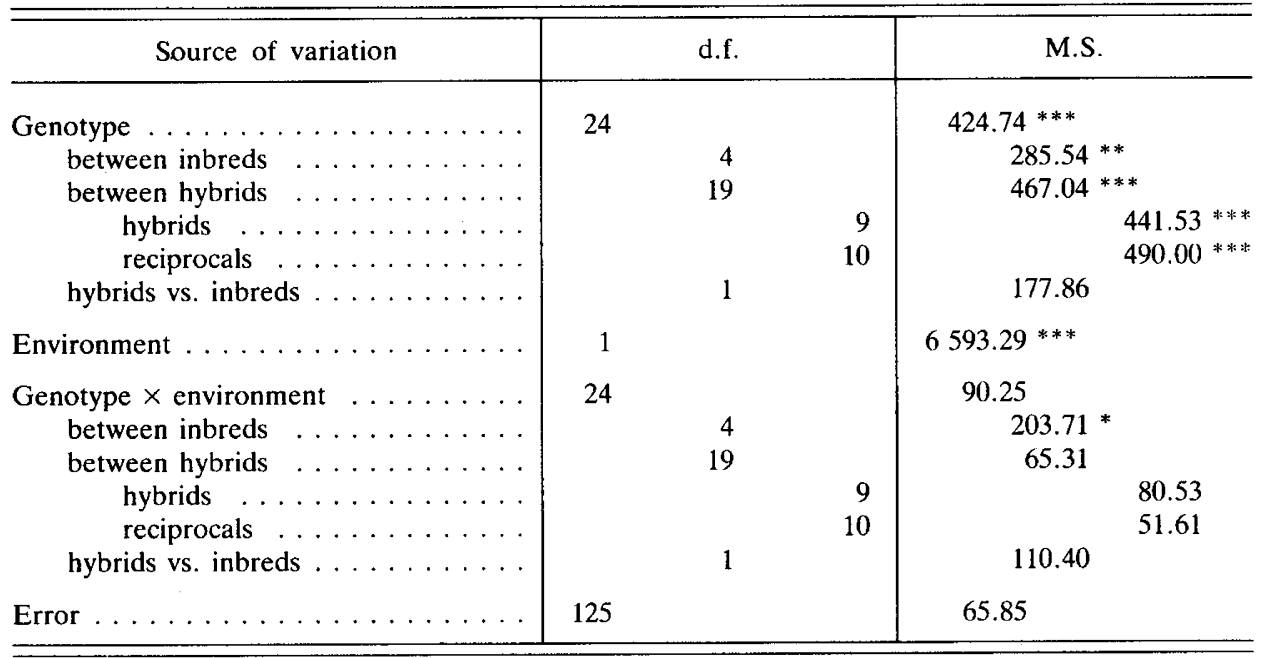

b) Rate of Development

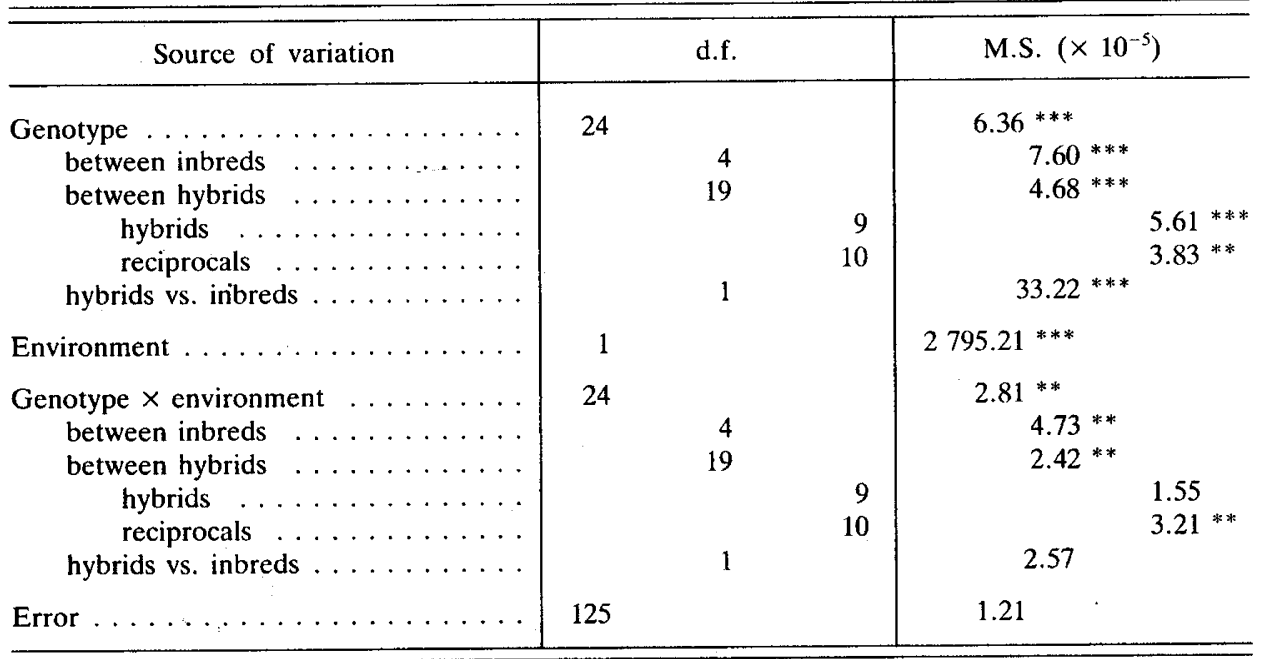


c) Fecundity

\begin{tabular}{|c|c|c|c|}
\hline Source of variation & d. & & M.S. \\
\hline 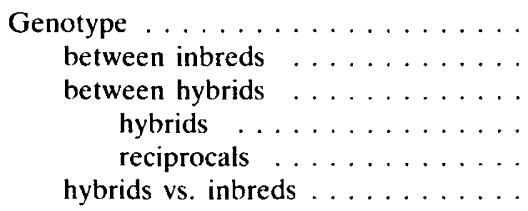 & 24 & $\begin{array}{r}9 \\
10\end{array}$ & $\begin{array}{c}1963.95 * * * \\
1322.72 * * * \\
947.75 * * * \\
1939.70 * * * * \\
54.98 \\
238.36 .77^{* * *}\end{array}$ \\
\hline Environment $\ldots \ldots \ldots \ldots \ldots$ & 2 & & $146139.00 * * *$ \\
\hline 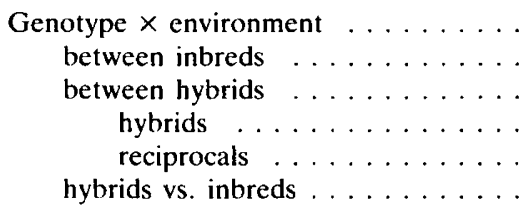 & 48 & $\begin{array}{l}18 \\
20\end{array}$ & $\begin{array}{l}414.7() * * * \\
177.93 * * * \\
200.09 * * * \\
224.44 * * * \\
178.17 * * * \\
5439.43 * * *\end{array}$ \\
\hline Error $\ldots \ldots \ldots \ldots \ldots \ldots$ & 300 & & 63.75 \\
\hline
\end{tabular}

${ }^{*} \mathrm{p}<0.05 ;{ }^{* *} \mathrm{p}<0.01 ;{ }^{* * *} \mathrm{p}<0.001$

Analysis of fecundity (table 2c) showed significant variation between inbreds, showing additive effects. Differences between hybrids were also significant, but not reciprocal differences. Heterosis was very important, as the hybrids vs. inbreds component shows. All the components of interaction were significant. The fact that the reciprocals component of interaction was significant but not the main reciprocals effect indicates that there must be some effect of reciprocals greatly dependent on the environment. The hybrids vs. inbreds component of interaction indicates that heterosis changes considerably with environments.

Table 3 shows the mean heterosis of each line pair for the traits and environments considered, (a), and the pooled mean heterosis, (b). For viability, only 2 pairs of lines showed significant positive heterosis under high density, while under optimum density one pair showed positive and another negative heterosis. Mean heterosis was significant $(\mathrm{p}<0.05)$ only under high density conditions.

The rate of development was higher for hybrids than for inbreds at optimal conditions in 8 of the 10 pairs of lines. Under high density conditions, the differences between lines and hybrids showed the same trend, although only 2 were significant due to the higher error variance of the estimates. Mean heterosis was also significant under optimum density and not under high density.

Heterosis for fecundity changed with environments as was shown by the analysis of variance (table 2c). Heterosis was higher in optimal conditions than in crowded development $(\mathrm{p}<0.001)$, and in both was much higher than at low temperature, where the mean pooled heterosis was not significant. 

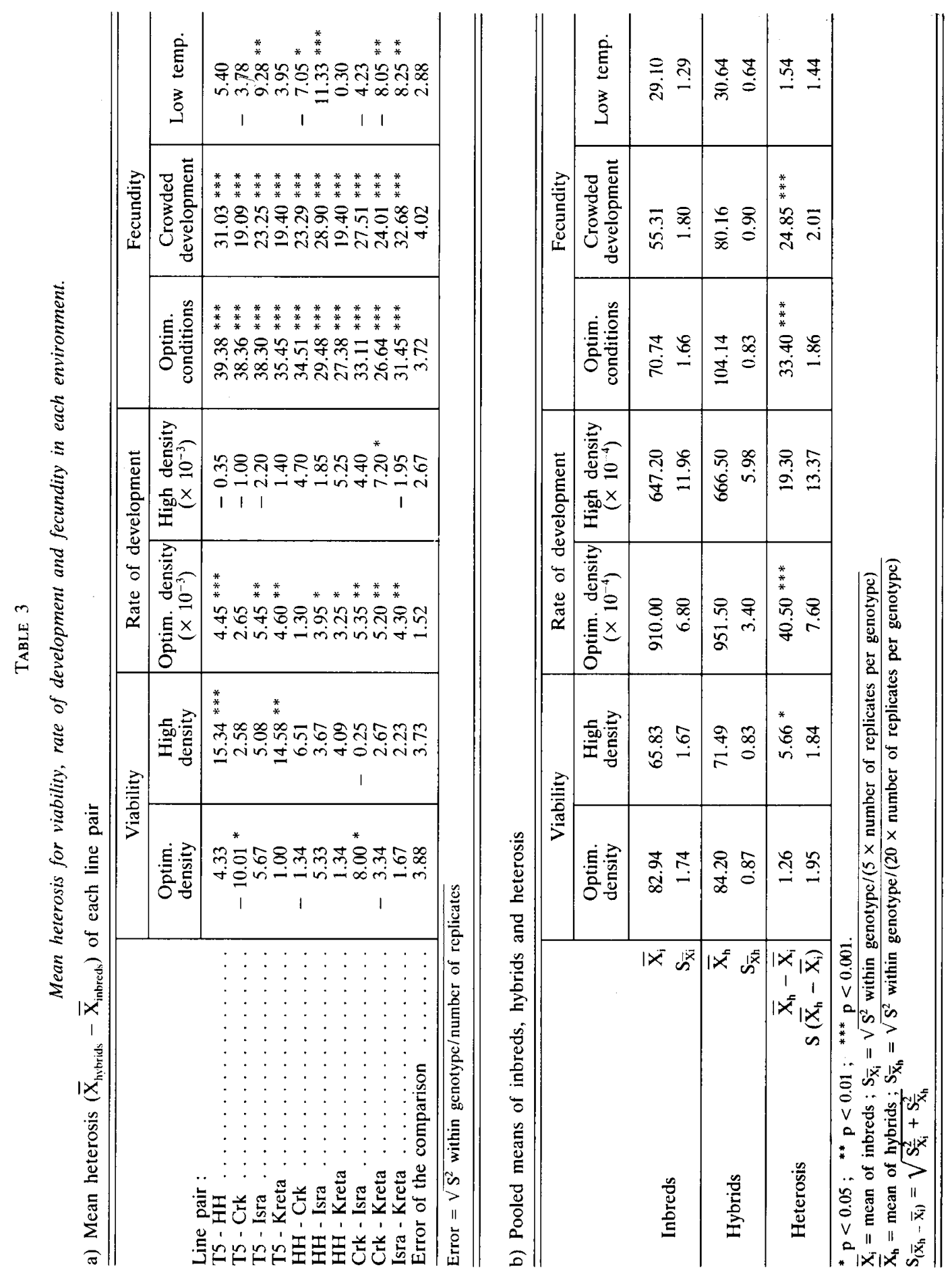


\section{Discussion}

Although the overall interaction was not significant for viability, the inbreds component was. Rate of development and fecundity also showed genotype $\times$ environment interaction, which is very common for most quantitative traits related to fitness in Drosophila (Prabhu \& RoBertson, 1961 ; TANTAwy et al., 1973). Heterosis for viability was significant $(p<0.05)$ under high density and not under optimum density conditions (table 3). Although the difference between these 2 estimates was not significant (as proven by the hybrids vs. inbreds component of interaction in table $2 \mathrm{a}$ ), it was of the same sign as in previous studies on viability (Parsons, 1959 ; FonTdEviLA, 1970 ; Young, 1971 ; TACHIDA \& MuKAl, 1985), that is, heterosis is higher under non-optimal environments.

Mean heterosis for the rate of development was highly significant $(p<0.001)$ under optirnum density, but not under high density, although the 2 values did not differ significantly (as shown by the hybrids vs. inbreds component of interaction in table $2 \mathrm{~b}$ ). So, it is difficult to draw solid conclusions about the heterosis dependence of environment for this trait, as well as for viability, due to the high error variances and small number of replicates. Another feature of heterosis was that hybrids had a lower error variance than inbreds under high density conditions.

The results on fecundity contrast with most other studies on environment-dependent heterosis, which have shown heterosis to be greater in suboptimal conditions. From our results it is clear that mean heterosis for fecundity was much larger under optimal than under stress environmental conditions. This was rather general for the ten different hybrids measured (table 3 ), indicating that hybrids were relatively more affected by environmental stress, particularly low temperature, than their inbred parents. Nevertheless, when environmental fluctuations represented uncontrolled minor departures from a given environment, the hybrids showed lower variability (table 1). Therefore, the greater homeostasis of hybrids to minor environmental fluctuations cannot be simply extended to major changes, but the magnitude of heterosis under environmental stress would depend on the trait being studied and the environmental stress to which the individuals are being exposed. These results agree with those of SANG (1964) for growth rate in Drosophila. Also, Barlow (1981) pointed out that, contrary to most traits and environmental variables, heterosis for growth is enhanced by favourable nutrition. Egg laying could be, to some extent, likened to growth, in that both traits are a measure of nutrient conversion. Nevertheless, Orozco \& BELL (1974a and b) showed the dominance variance to be much greater under low temperature stress compared with an optimum environment for egg laying by virgin females in Tribolium castaneum. On the other hand, BARLOW (1981) concluded from his review that heterosis for fecundity did not appear to display any directional tendency.

Finally, it is worth noting that we have found hybrids to exceed their inbred parents in vigour as well as in stability to minor environmental changes, although the lines were from very different origins. Therefore, the heterosis we have found can not be explained in terms of genic balance achieved through previous selection (e.g. Mather, 1955 ; Pavlosky \& Dobzhasnky, 1966). 


\section{Conclusions}

Although the generalization of this statement must be proven over a wider range of environmental stresses, our results show that heterosis for fecundity in Drosophila melanogaster is greater under optimal environment than under stress environments. The greater homeostatis of hybrids to minor changes in a given environment cannot be extended to major quantitative or qualitative changes in the environment that can involve the action of different sets of genes in each set of circumstances.

Received December 20, 1985.

Accepted July 3, 1986.

\section{References}

BARLOW R., 1981. Experimental evidence for interaction between heterosis and environment in animals. Anim. Breed. Abstr., 49, 715-737.

Clare J.M., LuckinbiLl L.S., 1985. The effects of gene-environment interaction on the expression of longevity. Heredity, 55, 19-26.

Dobzhansky Th., LeVEne H., 1955. Genetics of natural populations. XXIV. Developmental homeostasis in natural populations of Drosophila pseudooscura. Genetics, 40, 797-808.

Dobzhansky Th., Pavlovsky O., SpaAsky B., SPaAsky N., 1955. Genetics of natural populations. XXII. Biological role of deleterious recessives in populations of Drosophila pseudooscura. Genetics, 40, 781-796.

FontdeVILA A., 1970. Genotype-temperature interaction in Drosophila melanogaster. I. Viability. Genetica, 41, 257-264.

Lerner I.M., 1970. Genetic homeostasis. 134 pp., Dover Publ. Inc., New York.

Mather K., 1955. The genetical basis of heterosis. Proc. Roy. Soc., B. 144, 143-150.

Orozco F., Bell A.E., 1974a. A genetic study of egg laying of Tribolium in optimal and stress environments. Can. J. Genet. Cytol., 16, 49-60.

Orozco F., Bell A.E., 1974b. Reciprocal recurrent selection compared to within-strain selection for increasing rate of egg lay of Tribolium under optimal and stress conditions. Genetics, 77, 143-161.

Parsons P.A., 1959. Genotypic-environmental interactions for various temperatures in Drosophila melanogaster. Genetics, 44, 1325-1333.

Parsons P.A.. 1966. The genotypic control of longevity in Drosophila melanogaster under two environmental regimes. Aust. J. Biol. Sci., 19, 587-591.

Pavlovsky O., DobZhansky Th., 1966. Genetics of natural populations. XXXVII. The coadapted system of chromosomal variants in a population of Drosophila pseudoobscura. Genetics, 53, 843-854.

Prabhu S.S., Robertson F.W., 1961. The ecological genetics of growth. V. Gene-environment interaction and inbreeding. Genet. Res., 2, 424-430.

Robertson F.W., ReEve E.C.R., 1952. Homozygosity, environmental variation and heterosis. Nature, 170, 296.

Robertson F.W., ReEve E.C.R., 1955. Studies in quantitative inheritance. VIII. Further analysis of heterosis in crosses between inbred lines of Drosophila melanogaster. Z. Indukt. Abstamm. Vererblehre, 86, 439-458. 
Sang J.H., 1964. Nutritional requirements of inbred lines and crosses of Drosophila melanogaster. Genet. Res., 5, 50-67.

Snedecor G.W., Cochran W.G., 1967. Statistical methods. 703 pp., The Iowa State University Press, Ames.

TaChida H., Mukal T., 1985. The genetic structure of natural populations of Drosophila melanogaster. XIX. Genotype-environment interaction in viability. Genetics, 111, 43-55.

TANTAWY A.O., 1957. Heterosis and genetic variance in hybrids between inbred lines of Drosophila melanogaster in relation to the level of homozygosity. Genetics, 42, 535-543.

Tantawy A.O., Mourad A.M., Affifi E.L., 1973. Studies on natural populations of Drosophila. XIV. Gene-environment interaction in Drosophila melanogaster. Egypt. J. Genet. Cytol., 2, 244-257.

Young S.S.Y.. 1971. The effects of some physical and biotic environments on heterosis of direct and associate genotypes in Drosophila melanogaster. Genetics, 67, 569-578. 